a straightforward and non-technical way the foundations for the practical instruction which follows. Next come the principles of therapy and management, with sensible and sometimes original forms of treatment, and then follows a discussion of the various syndromes, all treated separately and comprehensively-pathogenesis, symptomatology, differential diagnosis, treatment, and so on. Each chapter has a useful list of references, and the text is enlivened throughout by humorous illustrations. This is not the place to discuss the ethics of humour in medical texts, suffice it to say here that these drawings are not only in excellent taste, but would prove extremely useful if reproduced for the patients, and have been, in fact, included for this purpose.

This work is more than a manual, however useful it may prove in medical practice, for the author makes clear the dangers in extreme attitudes -not only the cautious but the over-enthusiastic. His explanation of the non-psychogenic functional disorders has an important place in psychosomatic literature, and his theories, though simple, make sense of much that appears complicated when stated in more wordy prose. Good reading for student and experienced clinician alike, this book is specially recommended to those just entering general practice.

\section{SKIN GRAFTING}

By James Barrett Brown, M.D. and Frank McDowell, M.D. Third Edition. Pp. xv + 4I I, with 328 illustrations, and six colour plates. London. Pitman Medical Publishing Co. Ltd. 1958. £5 5s.

This book, the third edition, is an expanded work based on 'Skin Grafting of Burns,' by the same authors, published in 1943, and an intermediate volume, 'Skin Grafting,' of 1949 . The enlargement from some 200 pages in the first edition, and 332 in the second, is brought about by several means.

The subject of burns is dealt with in all its aspects, and this section has been expanded in the light of modern developments. Other chapters have been enlarged, and fresh ones added, notably those concerned with trauma in civilian life, and radiation burns.

The student of Plastic Surgery will find this a useful and readable book, which does not burden him with too much operative detail. In one relatively short section pedicle flaps of all kinds are explained clearly, together with their uses, and their preparation. The use of local flaps, as opposed to distant tube pedicles, is rightly emphasized, and the authors constantly point out the desirability of completing a surgical programme in the minimum number of operations.

There is much of a repetitive nature, especially in the burns section, and many of the photographs and illustrations, some of them rather poor, do tend to split up the text unnecessarily, and cause the readêr constantly to search among pages already read for diagrams quoted in the pages following.

The use of homografts in the severely burned patient is explained, and helpful suggestions are made regarding the organization of post morte skin banks. This section, together with that diss cussing radiation burns, and like injuries, is a most interesting and valuable addition, which , coute become of great importance in a national emergenc.

In any subsequent edition improvements in the presentation of this work should produce a firsts class book out of what is, at the moment, a good one.

\section{SURGERY OF THE SYMPATHETIC NERVOUS SYSTEM}

By Professor Sir James Paterson Ross, K.C.V.O

LL.D., M.S., F.R.C.S., F.R.A.C.S., F.A.C.S్ Third Edition. Pp. xii + 170, illustrated London: Baillère, Tindall \& Cox. 1958. 35\$

Twenty years ago Sir James Paterson Roş published the last edition of his book on the Surger of the Sympathetic Nervous System. A new edition after this lapse of time is most welcome This is a short book written by a master who, as result of long experience, knows what is important and what can be omitted. Surgeons will find that this is a monograph of great practical valug During the past decade sympathectomy has $\overline{6}$ sit much of its appeal, largely because it has bee performed too frequently and also on many un suitable patients. Sir James Paterson Ross corrects this impression and tells the surgeon the real valuog of this most useful operation.

\section{FUNGUS DISEASES AND THEIR TREATMENT}

Edited by R. W. RIDDELL, M.D.(Lond.), F.R.C.PS (Edin.), and G. T. STEWART, B.Sc., M.D.(Glas. D.T.M. \& H. Pp. xvii $+256+$ index, illus trated. London: Butterworth \& Co. Ltd. 1958 45s.

Mycology is a neglected subject in this countryo We largely depend on American authors for our textbooks and, while some of these are excellent and are based on wide experience, they tend $t \bar{\theta}$ leave a false impression of the frequency in thit country of the conditions described.

This book will help to restore a balanced poin of view at a time when the fungous diseases are growing in importance. It is not a true textbool nor a review; it is described by the publishers as work of reference but is, in fact, an edited serie of papers given in a symposium held at th Brompton Hospital in July 1957 . There are $2 \dot{2}$ articles on the pathology and epidemiology of the diseases and, in the second part, nine on treatment 